\title{
The fracture behavior transitions in cold dwell fatigue of
}

\section{Ti-6Al-4V}

\author{
Tomomichi Ozaki ${ }^{1}$, Yutaro Ota ${ }^{1}$, Keiji Kubushiro ${ }^{2}$, Kokichi Sano ${ }^{3}$
}

1 Technology platform center, IHI Corporation, 1,Shin-nakaharacho, Isogo-ku, Yokohama, Japan 2 IHI Asia Pacific Thailand, 11th and 12th Floor, Ramaland Building, 952 Rama IV Road, Suriyawongse, Bangrak, Bangkok 10500, Thailand

\begin{abstract}
$\underline{\text { Abstract }}$
Ti-6Al-4V forged materials which had fine grain size and commercial billet which had moderate grain size and micro texture were prepared. Cold dwell fatigue tests were conducted using both materials, and dwell time condition was up to 1800 s. Fracture cycles and elongation were almost same on each specimen. Number of cycle to failure decreased with increase of dwell time. Fracture elongation increased up to dwell time of $10 \mathrm{~s}$, and it was constant in over 10s. Fracture surface were observed. In short time dwell condition up to $2 \mathrm{~s}$, fracture surface showed fatigue type. Fracture surfaces changed to dimple in over $10 \mathrm{~s}$ dwell. In billet material, facets were observed in inner area of fracture surface.
\end{abstract}

\section{Introduction}

Titanium alloys have been used as important rotating parts of gas turbine engine known because of lightweight, excellent mechanical properties, and corrosion resistance. On the other hand, fatigue properties are affected by several factors. Especially hold of load during cyclic loading at ambient temperature decrease fatigue life significantly. It is known as cold dwell fatigue (CDF) [1-12]... CDF properties was investigated precisely on many kinds of alloy such as IMI685, IMI834 [1, 2], and Ti-6262 [3]. From these reports, it have been clarified that fatigue life decrease with dwell is remarkable in following conditions, stress revel: over $85 \%$ yield stress, stress ratio: close to 0 , temperature: up to $100^{\circ} \mathrm{C}$. In addition, detail fracture surface analysis revealed that it was reported that facets in $\alpha$ grains occur at fracture initiation site [1, 2, and 13]. Furthermore, it was recently reported that CDF properties and fracture behavior are affected by microstructure such as micro texture [].

On the other hand, such fatigue mode including dwell of other material is recognized as creep-fatigue $[14,15]$. On usual materials such as steel, aluminum and copper, creep fatigue occurs at elevated temperature which is enough to creep. In case of titanium alloys, it is reported that creep occurs at ambient temperature $[10,13]$. Therefore, it is considered that CDF properties and fracture morphologies of titanium alloys are strongly affected by room temperature creep. Thus, this study intends to investigate the fracture behavior with several dwell time conditions and microstructure.

\section{Material and experiments}

Ti-6Al-4V Plate which was forged at $850^{\circ} \mathrm{C}$ into $30 \mathrm{~mm}$ thickness from bar which was ASTM 48xx, and commercial forged 10" billet were prepared for cold dwell fatigue test. Forged plate and billet was used for mechanical test without heat treatment. Tensile test and dwell fatigue test were conducted at room 
temperature. Test specimens of tensile and fatigue were a same diameter of $6 \mathrm{~mm}$ and a gauge length of 30 $\mathrm{mm}, 40 \mathrm{~mm}$ respectively. Long axis of Test specimens machined from Bar were parallel to longitudinal of Bar. LCF and dwell fatigue tests were performed with a triangular waveform for the LCF test and a tensile-stress-retained trapezoid waveform for the dwell fatigue test, and other conditions were

following: $\mathrm{R}=0$, maximum stress of $876 \mathrm{MPa}$, at air. Dwell time changed from $2 \mathrm{~s}$ to $1800 \mathrm{~s}$.

\section{$\underline{\text { 3. Results and Discussion }}$}

Figure 1 shows microstructure of forged plate and billet. Both materials were equiaxed $\alpha$ type, and grain size of forged plate and billet were about $10 \mu \mathrm{m}, 30 \mu \mathrm{m}$ respectively. And $\alpha$ volume fraction of both materials were over 90\%. Figure 2 shows grain orientation map analyzed by EBSD. In a billet material there were micro texture by which the resemble orientations of $\alpha$ phase gathered (pointed at arrowed point), and its width was about $500 \mu \mathrm{m}$ at maximum. in contrast, $\alpha$ grain orientation were dispersed homogenously compared with billet.
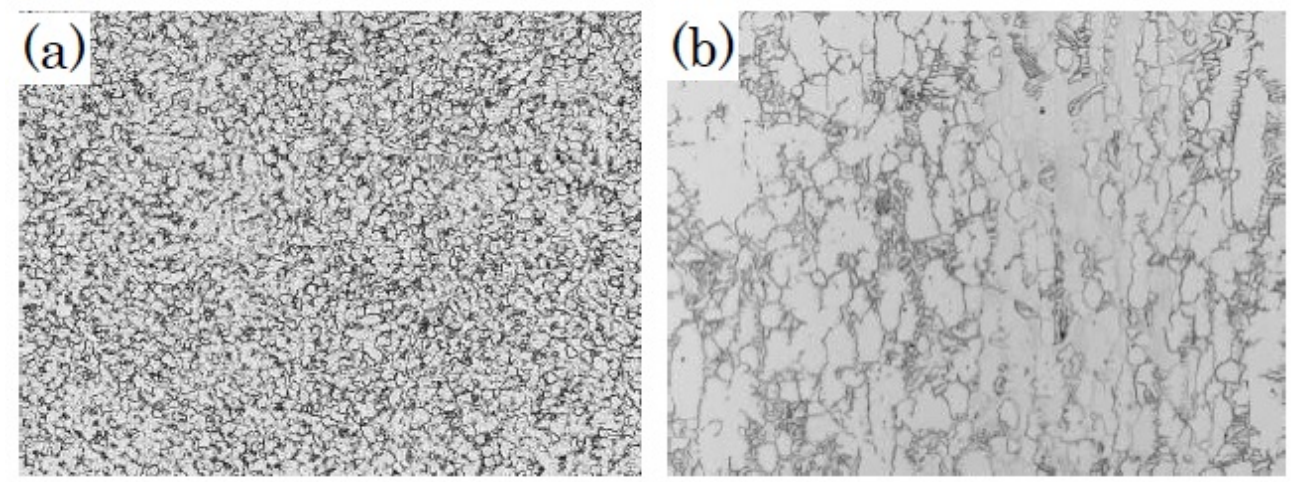

\section{$100 \mu \mathrm{m}$}

Fig. 1 Optical microstructure of prepared material, (a) forged plate, (b) billet
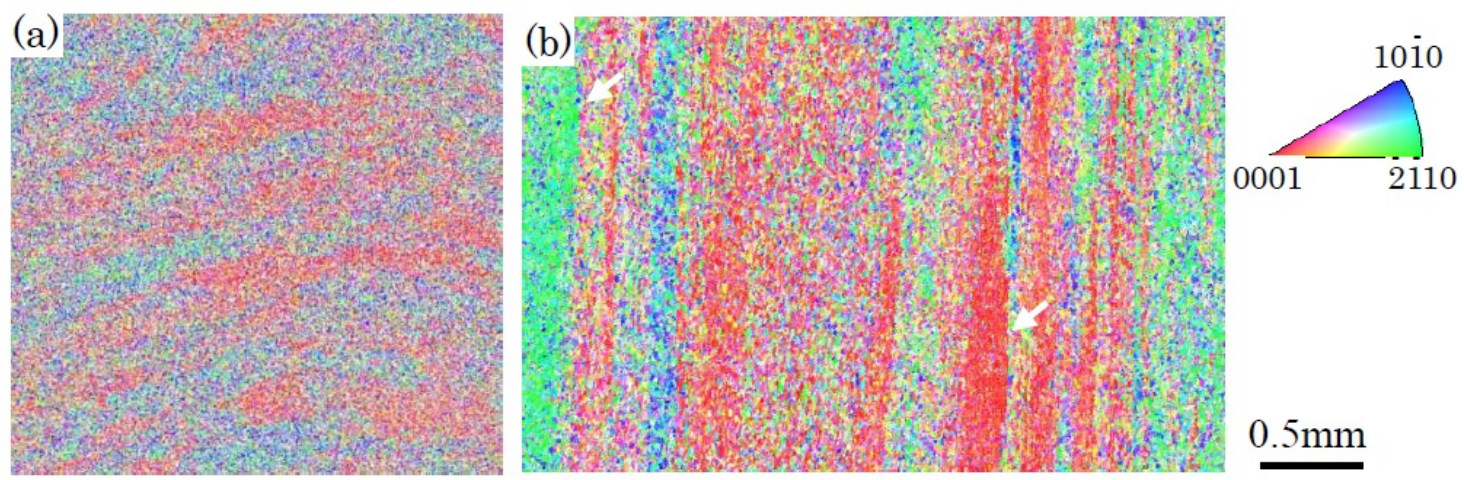

Fig. 2 Grain orientation map, (a) forged plate, (b) billet

Tensile properties were listed in Table 1. $0.2 \%$ yield stress of forged plate was higher than billet, and elongation was almost same. Figure 3 shows the fatigue test results in several dwell time conditions.

Number of cycles to failure decreased with increase of dwell time up to 1800 s, forged plate and billet showed almost same fatigue life. Figure 4 shows the fracture elongation with dwell time. Fracture elongation gradually increased with increase of dwell time up to $10 \mathrm{~s}$, and it was constant of about $18 \%$ in over $10 \mathrm{~s}$ dwell region. Fracture elongations of both materials were also almost same in all dwell time conditions. 
Table 1 Tensile properties of each material

\begin{tabular}{||l||cc||}
\hline & $0.2 \%$ yield stress & fracture elongation \\
\hline Forged plate & $950 \mathrm{MPa}$ & $14.0 \%$ \\
billet & $917 \mathrm{MPa}$ & $14.6 \%$ \\
\hline
\end{tabular}

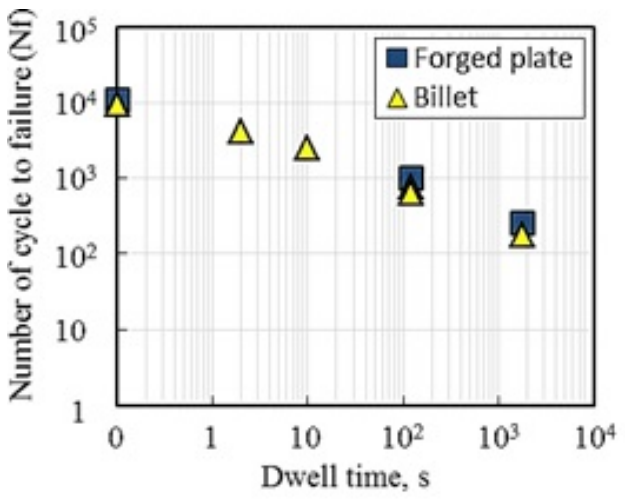

Fig.3 Number of cycle to failure of CDF test

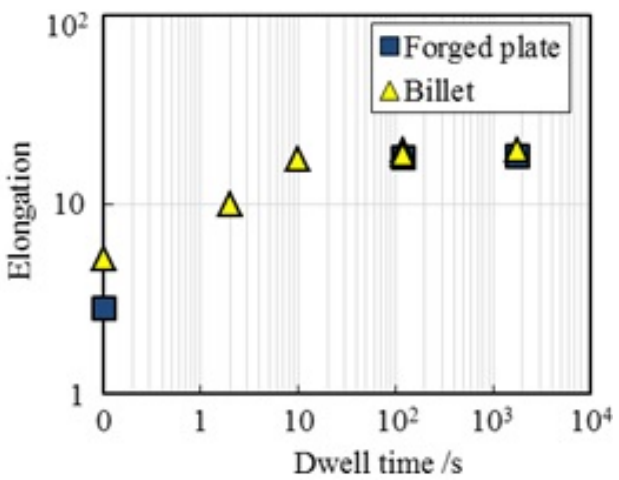

Fig. 4 Fracture elongation of CDF test

Figure 5 and 6 shows fracture surfaces of forged plate and billet specimens with all dwell time conditions. In case of short dwell time conditions, 0s (fig. 5 (a) and fig. 6 (a)) and 2s (fig.6 (b)), there were flat and smooth area on fracture surfaces. River patterns were observed in these specimens, and crack initiation was started at surface of specimens (pointed by black arrow). Facets were observed at crack initiation point and striations were in crack propagation area. In contrast with that, fracture surfaces of specimens with dwell time of over $10 \mathrm{~s}$ were rough. In these specimens, dimples were mainly observed on each fracture surface. Furthermore, small flat surfaces were locally in billet specimen (circled by white dot line). Figure 7 shows SEM images of the flat area which was observed in billet specimens of $10 \mathrm{~s}$ and 1800s dwell time conditions. Quasi cleavage facets were observed at these local flat areas. Small amount of striations were in the neighborhood of facets. These quasi - cleavage facets were in inner of specimens not surface. In forged plate specimen, facets hardly existed.

It was reported that fracture morphology changes from fatigue which consist of crack initiation facets and striation to ductile fracture which is caused by static loading with increase of dwell []. In our results fracture surface changed from facets and striation into dimples, therefore over 10s dwell results in ductile rupture in both material. Furthermore, small facets were observed in only billet specimens. It is considered to be effected by micro texture. In micro texture area, slip and deformation are localized in textured area because slip systems of $\alpha$ phase are limited by its crystal structure. Therefore, the some $\alpha$ colonies which has unfavorable orientation for load axis hardly deform and show facet fracture surface []. Billet material had micro texture, and size of facets which were observed in CDF specimens with longer dwell was not so large and corresponding to micro texture width. Therefore, these micro textures are considered to affect on CDF life, but the fatigue live of both micro textured and no textured material were almost same.
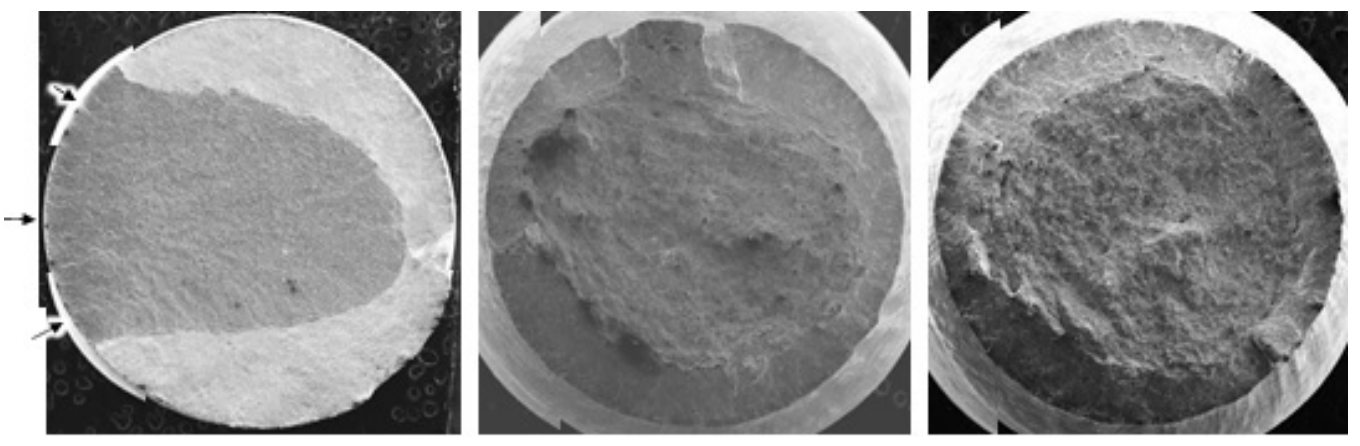

Fig. 5 Fracture surface of Forged plate after CDF test. 

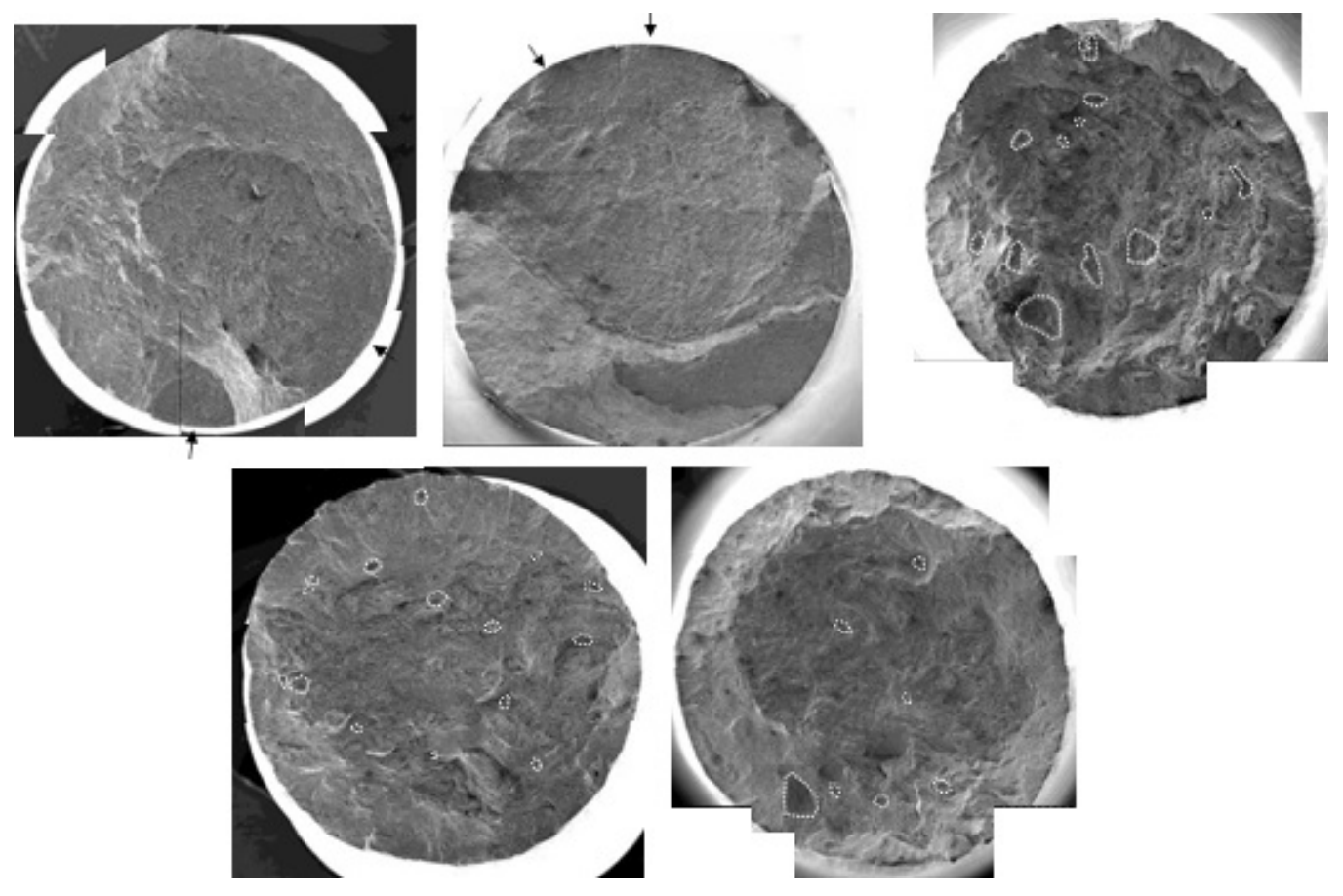

Fig. 6 Fracture surface of billet after CDF test.

Dwell time (a) 0s, (b) 2s, (c) 10s, (d) 120s, (e) 1800s
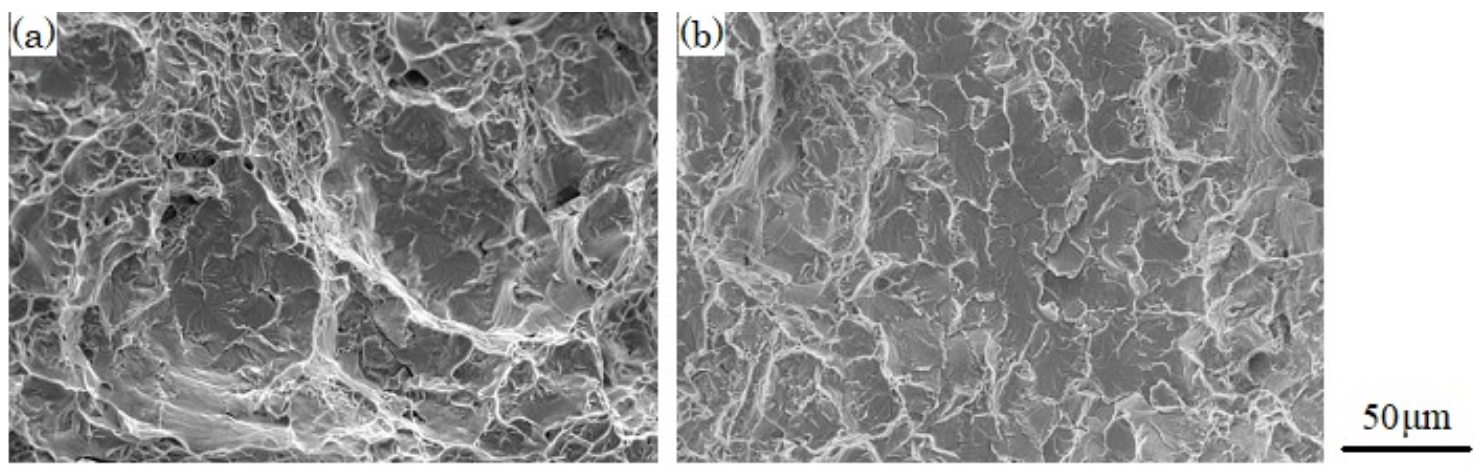

Fig. 7 Facets of longer dwell specimen, (a) 10s, (b) 1800s

\section{Conclusion}

In this study cold dwell fatigue tests were performed and fracture surfaces were analyzed in order to clarify the effect of CDF condition and material microstructure on fracture morphology. Fracture cycles decrease with increase of dwell time, and fracture elongation increase up to 10s of dwell. Fracture surface morphology changed from fatigue into ductile fracture corresponding to elongation change. In billet material, facets were observed on fracture surface of $10 \mathrm{~s} \sim 1800$ s dwell specimens. 
[1] M. R. Bache, Int. J Fatigue 25 (2003) 1079-1087.

[2] M. R. Bache, M. Cope, H.M. Davies, W.J. Evans, G, Int. J Fatigue 19 (1997) S83-S88.

[3] V. SINHA, M.J. MILLS, J.C. WILLIAMS, Metal \& Mater. Trans. A 35 (2004), pp. 3141-3148.

[4] A.L. PILCHAK and J.C. WILLIAMS, METALL. MATERIALS TRANS. A (2011), pp.1000-1027.

[5] L. Yang, J. Liu, J. Tan, Z. Chen, Q. Wang, R. Yang, J Mater. Sci. Tech. 30 (2014) 706-709.

[6] M.L. Thomsen, D.W. Hoeppner, Int. J Fatigue 20 (1998) 309-317.

[7] J. Peng, C.Y. Zhou, Q. Dai, X.H. He, Mater. and Design 71 (2015) 1-16.

[8] V. Chandravanshi, K. Prasad, V. Singh, A. Bhattacharjee, V. Kumar, Int. J Fatigue 91 (2016) 100-109.

[9] Z. Zheng, D.S. Balint, F. P.E. Dunne, Journal of the Mechanics and Physics of Solids 107 (2017) 185- 203.

[10] I. Bantounas, T.C. Lindley, D. Rugg, D. Dye, Acta Materialia 55 (2007) 5655-5665.

[11] S. Hemery, P. Villechaise, Metal \& Mater. Trans. A 697 (2017) 177-183.

[12] F. Wang, W. Cui, Mater. Sci. and Eng. A 642 (2015) 136-141.

[13] A.L. PILCHAK and J.C. WILLIAMS, METALL. MATERIALS TRANS. A (2011), pp.1000-1027.

[14] J. Wareing, Metall. Trans. A (1977), pp. 176-181.

[15] S. S. Manson, Int. J. Fracture Mechanics, (1966), pp 327-327. 